Katarzyna Pekacka

\title{
Moralność i polityka albo Max Weber o cnocie
}

$Z$ pewnościq polityka nie jest zajęciem etycznym. Istnieje wszelako pewna minimalna miara wstydu i przyzwoitości, której także w polityce nie narusza się bezkarnie.

M. Weber,

Prawo wyborcze i demokracja w Niemczech

Czy istnieje jakiś specjalny rodzaj moralności politycznej? Czy państwo demokratyczne może obejść się bez zakorzenienia w przeddemokratycznych zasadach moralnych, uświęconych przez religię, tradycję i obyczaje?

Gdzie szukać moralnych podstaw demokracji, bo przecież demokracja - bardziej niż inne systemy - wymaga oparcia w wartościach i dojrzałej kultury politycznej społeczeństwa?

Na pierwszy rzut oka politykę od moralności dzieli przepaść. Wszak polityka nie była i nie jest przedsięwzięciem moralnie ufundowanym i uzasadnionym; ma do czynienia nie tyle ze swoistymi, podejrzanymi etycznie celami, co raczej - i przede wszystkim - osobliwymi środkami ich realizacji: przemoca przymusem, pótprawdą czy zdradą. Mikołaj Bierdiajew pisał: „polityka w 9/10 jest zawsze kłamstwem, oszustwem i fikcja. I tylko $1 / 10$ polityki zawiera w sobie element realności - urzeczywistnienia władzy koniecznej dla istnienia wszechświata, władzy pochodzącej od Boga"'. Bo o ile postępowanie moralne oznacza zasadniczo skierowanie ku dobru, o tyle działanie polityczne kojarzy się z tym, co najgorsze $-\mathrm{z}$ etyczną nobilitacją występku. Wydaje się oczywistym, że

\footnotetext{
${ }^{1}$ M. Bierdiajew, Nowe średniowiecze, Komorów 1997, s. 137.
} 
polityka rządzi się własnymi regułami, które $\mathrm{z}$ moralnością mają niewiele wspólnego. Czy tak jest $w$ istocie? Odpowiedzi na to palące pytanie poszukamy u Maxa Webera.

\section{Tradycja, wspólnota i punkt widzenia}

(...) wlaśnie $w \dot{z} y c i u, w$ tym, co dla Platona bylo gra cieni na scianie jaskini, pulsuje prawdziwa rzeczywistość, wszystko inne zaś to wywiedzione z niej martwe widma.

M. Weber, Nauka jako zawód i powotanie

Świadomość własnej tradycji, czyli historii własnej wspólnoty, jest warunkiem niezbędnym samoświadomości ludzkiej. Co więcej, będzie to istotny warunek racjonalnej ${ }^{2}$, toczącej się w ramach danej tradycji debaty, dotyczącej celów życia i środków ich osiagania, definiowania wspólnego dobra. Jak zauważył w swoich esejach politycznych Max Weber, nie istnieje racjonalność, która nie byłaby racjonalnością jakiejś określonej tradycji i określonej wspólnoty, a przez to nie byłaby - równocześnie - racjonalnością odmienną od racjonalności innej wspólnoty, jej tradycji i jej języka. Każda bowiem racjonalność jest konstytuowana (a może i konstruowana) przez jakieś tradycje, sama je podtrzymuje i zapewnia ich przyszłe trwanie. I chociaż M. Weber pisze, że „najwyższe i ostateczne (...) ideały są zmienne i przemijające”, że chociaż „nie można narzucić ich przyszłości”, to jednak trzeba „pragnać, aby "nasze» właściwości rozpoznała [przyszłość] jako właściwości swoich "własnych» przodków. My, z «naszą» pracą $\mathrm{i}$ "naszym» charakterem, chcemy być przodkami przyszłego pokolenia" i dlatego właśnie ,polityka (...) «niemieckiej»

${ }^{2}$ Interpretowany podmiot działa racjonalnie, czy też teleologicznie, wtedy gdy podczas swych działań posiłkuje się swoją wiedzą oraz własnym systemem wartości i przekonań. Na potrzeby swej pracy przyjmuję klasyczną definicję - racjonalności, która głosi: „Jeżeli podmiot $\mathrm{X}$ w czasie $\mathrm{t}$ ma podjąć jedną $\mathrm{z}$ czynności $\mathrm{C}_{1}, \mathrm{C}_{2} \ldots \mathrm{C}_{\mathrm{n}} \mathrm{i}$ czynności te na gruncie wiedzy podmiotu $\mathrm{X}$ w czasie $t$ prowadzą odpowiednio do rezultatów $R_{1}, R_{2} \ldots R_{n}$ (przy czym czynności te dopełniaja się $\mathrm{i}$ wzajem uzupetniaja, a w rezultacie uporządkowane są przez charakterystyczną dla $\mathrm{X}$ relacje preferencji), to $\mathrm{X}$ podejmie czynnosć maksymalnie preferowanq̨". 
państwowości, podobnie jak kryteria, którymi posługuje się «niemiecki»» teoretyk (...), moga być tylko "niemieckie»"” [wyróżn. - K. P.].

Innymi słowy, nie ma ucieczki od pułapki subiektywizmu, a w konsekwencji, relatywizmu - lub słabiej - perspektywizmu'; nie moźliwe jest bowiem sprowadzenie wszelkich schematów pojęciowych do jednego lub dokonania ich pełnego przekładu, ich całkowitej wzajemnej translacji. Jak mówil Protagoras, nie ma mniemań bardziej lub mniej prawdziwych, są tylko lepsze lub gorsze ( $z$ danej perspektywy). Uważam przeto, że w pismach politycznych $M$. Webera epistemologicznie zdefiniowana idea prawdy ostatecznej, czy - jak kto woli - słuszności absolutnej, staje się fikcja, nieosiagalnym, niemożliwym ideałem, który przez swą nierealność nie będzie miał dla nas żadnego konkretnego znaczenia. Dlaczego? Zwycięstwo jednej tradycji w rywalizacji z innymi nie może stanowić absolutnej gwarancji jej słuszności; „zależnie od przyjetego (...) stanowiska jedno jest dla człowieka diabłem, a drugie Bogiem - on sam musi o tym «zadecydować»" [wyróżn. - K. P.].

Szanowny Czytelnik z pewnością nie raz zauważył, że powodem sporów politycznych, politycznej agon, stają się różne definicje sytuacji, różna waga przywiązywana do tych samych faktów, a także różne interpretacje tych samych faktów, odmienne konsekwencje $z$ nich wyprowadzane oraz odmienne poglądy na związki między nimi. Bo, co tu kryć, politycy mniej albo bardziej świadomie, czasem zaś nieświadomie, biorą pod uwage pewne fakty, a inne pomijają. Fakty stają się w debatach politycznych nie czymś danym raz na zawsze, czymś danym obiektywnie, lecz sa środkami do przeforsowywania własnego punktu widzenia lub też, w najlepszym wypadku, okazują się być stanami rzeczy formowanymi politycznie. Przy czym - dodajmy - powodem odmiennych interpretacji jest nie tylko odmienność interesów czy dóbr, lecz również odmienność percepcji rzeczywistości - czynniki poznawcze i wartościujące. „Wynika z tego, «że niemoźliwe do pogodzenia wartości moga

${ }^{3}$ M. Weber, Polityka jako zawód i powolanie, Kraków 1998, s. 184.

${ }^{4}$ Nie zgadzam się ze stanowiskiem Reinharda Bendixa, który twierdzi, że Weberowi udało ,ustrzec się od relatywizmu (...) stawiając etyczne żądanie, by każdy formułował wyraźnie swą własną pozycję wartościującą w kategoriach jej wewnętrznej spójności i z pełną świadomością jej ostatecznych konsekwencji" (idem, Max Weber. Portret uczonego, Warszawa 1974, s. 236). Według mnie jest to strategia krótkoterminowa, pozwalajacca - i tak - na częste zmiany stanowiska, optyki, perspektywy etc., a w konsekwencji na lawirowanie pomiędzy zbiorami sprzecznych, wykluczających się wzajem reguł oraz wartości.

${ }^{5}$ M. Weber, op. cit., s. 132. 
współistnieć $\mathrm{z}$ przyjęciem tego samego $-\mathrm{z}$ czyjegoś punktu widzenia $[\mathrm{K}$. P.] - zbioru założeń i faktów»" ".

W tym właśnie sensie polityka coraz głębiej wkracza w dziedzinę semantyki, dotyczy bowiem definicji zjawisk, a do definicji należą konstatacje faktów, ich ocen oraz decyzje dotyczące podjęcia określonego typu działań. Niemal każde działanie staje się dzisiaj działaniem politycznym i każde formułowanie sądu ma wydźwięk polityczny. Jak pisał Marian Orzechowski: „umiejscowienie określonych zjawisk w całokształcie życia społecznego, w konkretnej sytuacji historycznej - a nie abstrakcyjne rozważania o ich naturze $\mathrm{i}$ istocie - sprawiaja, iż podział zjawisk na "polityczne» $i$ «niepolityczne» staje się w dużej mierze umowny"?. Dlaczego? Zjawiska społeczne nabierają cech zjawisk politycznych jedynie wtedy, gdy zostają uwikłane w sferę wartości, ocen i celów, w walkę o nie i w walke o władzę. Przy czym pamiętać należy, że rzeczywistość polityczna nie jest nam dana jako taka, że jest li tylko wytworem procesu poznania, stanowi bowiem cząstkę irracjonalnego chaosu, jakim ma być otaczający nas kosmos. Polityka jest tym, co mianem polityki określać będziemy: istnieje jedynie w świecie mówienia, myślenia i postaw. Albowiem to właśnie ludzie nadają rzeczywistości atrybuty polityczności, definiując ją tak, a nie inaczej ze względu na swoje cele, wartości i doświadczenia. Jak pisał $M$. Weber: „cecha (...) kwalifikująca dany proces jako społeczno-ekonomiczny, nie jest czyms, co zawsze jest w owym procesie jako takim «obiektywnie»; jest ona raczej uwarunkowana kierunkami naszego zainteresowania poznawczego, wynikajacego ze swoistego znaczenia kulturowego, nadawanego danemu procesowi"8.

Bo bardziej pierwotne od interesów, wartości, a nawet od faktów są punkty widzenia, czyli całościowe ramy interpretacyjne, w obrębie których cele, wartości i fakty sq wzajemnie dopasowywane oraz wiązane w kompleksy znaczeń. Różnice interesów i dóbr to wynik różnych wizji świata, a nie odwrotnie. Dopiero analiza tych wizji umożliwia nam zrozumienie różnic w interesach i szans na uniknięcie konfliktów w wyniku ich zderzenia. W takiej koncepcji polityki różnice miedzy celami a środkami stają się względne, albowiem często właśnie fakty i środki wpływają na formułowanie celów lub same stają się celami w sobie.

${ }^{6}$ R. Brown, Socjologia, [w:] Przewodnik po wspólczesnej filozofii politycznej, red. R. Goodini, P. Petit, Warszawa 1998, s. 135.

${ }^{7}$ M. Orzechowski, Polityka, wladza, panowanie w teorii Maxa Webera, Warszawa 1984, s. 126.

${ }^{8}$ M. Weber, op.cit., s. 141. 
Jak mniemam, Czytelnik zdążył się już zorientować, że staram się tu przemycić tezę, iź w ujęciu $M$. Webera interesy, cele i dobra nie są czymś danym pierwotnie i nie stanowią dla polityki ani punktu wyjścia, ani - tym bardziej - punktu odniesienia, gdyż są formułowane w trakcie działań. Ale również stan faktyczny nie istnieje jako niezależny od poglądów i punktów widzenia podmiotów. „W rzeczywistości społecznej, nie ma bowiem w zasadzie zjawisk sterylnie jednorodnych, "czystych», każde $\mathrm{z}$ nich jest $\mathrm{z}$ reguły wieloaspektowe"9. Fakty składają się na sytuacje, które są nieokreślone i problematyczne dla działających jednostek i w związku z tym różnie dookreślane, definiowane i oceniane, następuje ich wyraźna polityzacja. To nieokreślenie jest zawsze relatywne do punktów widzenia, do całościowych obrazów świata i poglądów na problemy podmiotów działających. I właśnie na podstawie tych całościowych wizji formulowane są konkretne programy działań oraz interpretowane fakty.

Moim zdaniem racjonalność staje się w weberowskich esejach niczym więcej jak tylko sprawą opcji i wizji ogólnych, sprawą wyboru a nawet doboru - perspektywy. Polityka jest zatem pojmowana jako rodzaj twórczości polegającej na precyzacji oczekiwań i przekonań jednostek oraz na konkretyzacji owych oczekiwań i przekonań w postaci propozycji, postaw i celów interpretacji. Sama zaś walka polityczna okazuje się być li tylko walką o uznanie wlasnego punktu widzenia: własnych definicji problemów i sposobów ich rozwiązań, własnych interpretacji faktów, określenia granic danego zjawiska, jego natężenia, stopnia niebezpieczeństwa, który jest $\mathrm{z}$ nim związany oraz poglądu na jego rozwój w przyszłości...

W tym miejscu dociekliwy Czytelnik powinien zapytać, czy w takim razie konflikt między sprzecznymi racjami i wartościami różnych wspólnot, kultur, tradycji, czy chociażby jednostek może zostać racjonalnie rozwiązany? Odpowiedź brzmi: nie. Jak pisał Alasdair MacIntyre, „tu trzeba wybierać - musimy wybierać pomiędzy partiami, klasami, narodami, racjami, ideałami”, przy czym "wybór określonego stanowiska wartościujacego lub zobowiazania nie może być bardziej racjonalny niź wybór któregokolwiek innego. Wszystkie wyznania wiary i wszystkie oceny sq̨ równie nieracjonalne, wszystkie sq subiektywnymi kierunkami narzuconymi na sentymenty i uczucia" ${ }^{10}$. Przekonanie o nieredukowalności pluralizmu racji tudzież pluralizmu wartości, stanowi $\mathrm{w}$ istocie

${ }^{9}$ Ibidem, s. 126.

${ }^{10}$ A. MacIntyre, Dziedzictwo cnoty. Studium z teorii moralnosici, Warszawa 1996 , s. 65. 
główny i uporczywy temat politycznych dociekań M. Webera. I tu najwyraźniej uwidacznia się - wedhug mnie - duchowe powinowactwo $M$. Webera z Fryderykiem Nietzschem. Dlaczego? „Do każdej moralności należy pewien określony sposób analizy uczynków i każdy jest f a 1 s z y w y. Jednakże każda moralność ma wlasne perspektywy i oświetlenia - swoja nauke o «motywach»"11.

\section{Odpowiedzialność i powolanie do polityki}

Jakim trzeba być człowiekiem, by móc kłaść ręce w szprychy historii?

M. Weber, Polityka jako zowód i powotanie

„Problemy i dylematy przejawiajace się w obrębie porządku politycznego mają stałe, tematyczne jądro, które można dramatycznie wyrazić surowymi słowy: sila jest zawsze <diaboliczna>, nigdy neutralna czy lagodna"'2. Nim jednak wkroczymy w sferę naszych dalszych dociekań, musimy, drogi Czytelniku, zaznaczyć, że moralność nie może istnieć oderwana od rzeczywistości, a każdy sąd moralny wiązać się musi z roszczeniami wobec praktyki. W przeciwnym razie sądy moralne byłyby tylko luźna, sytuacyjną wypowiedzia, powiazzaną z niezobowiazująca do niczego preferencją. Moralność musi zatem zawsze znajdować swe odbicie w czynie.

Jednak jak bardzo dobrze wiemy, „każda próba urzeczywistnienia jakiejś wartości środkami politycznymi podlega logice działania politycznego, które w tej czy innej formie musi uciekać się do przemocy jako środka i którego końcowy rezultat - nierzadko [przyp. -K. P.] - pozostaje (w calkowicie nieadekwatnym, często zgoła paradoksalnym stosunku do jego pierwotnego sensu»"13. Wynika z tego, że prymat etyki nad polityka oraz umoralnienie polityki $z$ punktu widzenia nie celów politycznych i politycznie pożądanych przedsięwzięć, ale odwiecznych, niezmiennych,

${ }^{11}$ F. Nietzsche, [w:] M. P. Markowski, Nietzsche. Filozofia interpretacji, Kraków 1997, s. 138.

${ }^{12} \mathrm{~L}$. A. Scaff, Fleeing the iron cage. Culture, politics and modernity in the thought of Max Weber, Berkley 1991, s. 166.

${ }^{13}$ Z. Krasnodębski, Max Weber, Warszawa 1999, s. 86; M. Weber, op. cit., s. 98 . 
uniwersalnych norm i wartości, genezą swą sięgających religii (etyka absolutna), będzie - co najmniej - niewskazane, by nie powiedzieć szkodliwe. Bo polityka to walka, w której nie znajdą zastosowania nakazy płynące $z$ Kazania na Górze: owe bezwarunkowe i jednoznaczne normy etyki ewangelicznej, kierującej się zasadami: niech „mają tak za tak, a nie za nie; bez światłocienia". Jak pisat M. Weber: „świat jest rządzony przez demony (...); kto obcuje $z$ polityka, to znaczy używa władzy i przemocy, ten zawiera pakt $z$ mocami diabelskimi. Jeżeli chodzi o działanie polityczne nie jest więc prawda, że $z$ dobra tylko dobro może wyniknąć, a ze zła tylko zło, lecz wręcz przeciwnie. Kto tego nie widzi, ten jest dzieckiem pod względem politycznym"14, i dalej: w polityce „osiaganie «dobrych» celów jest w wielu wypadkach związane ze zgodą na użycie moralnie watpliwych lub co najmniej niebezpiecznych środków, jak również z tym, że możliwe lub też prawdopodobne są złe skutki uboczne. I żadna etyka świata nie może przesądzić, kiedy i w jakim zakresie etycznie dobry cel «uświęca» etycznie niebezpieczne środki i skutki uboczne"15.

Co zatem? Tak, jak zdolność wirtuozowskiego dokonania ofiary $\mathrm{z}$ intelektu jest podstawową cechą człowieka rzeczywiście religijnego ${ }^{16}$, tak zdolność złożenia ofiary z sumienia wyróżniać będzie dobrego polityka. Pytasz, mój drogi Czytelniku, co pozostanie w świecie wyzutym $\mathrm{z}$ wszelkich wartości? Odpowiedzialność! Bo ,honor (...) polityka (K. P.) polega właśnie na wyłącznej odpowiedzialności osobistej jaką ponosi on za własne czyny. Odpowiedzialności «nie może» on - $\mathrm{i}$ «nie wolno» mu - nie przyjąc albo się jej pozbyć (...). Ludzie o predyspozycjach urzędniczych, nienaganni pod względem moralnym, są złymi politykami, przede wszystkim są politykami nieodpowiedzialnymi w politycznym rozumieniu tego stowa $i$ w tym sensie ich kwalifikacje moralne sa niskie"17 [wyróżn. - K. P.].

Weber twierdzi, że tylko dzięki politycznej odpowiedzialności możliwe jest autentyczne życie publiczne. Odpowiedzialność to akces polityka do świata współpracy: do świata, w którym każdy ma odgrywać przypisaną mu, dobrowolnie przyjętą rolę $\mathrm{i}$ gdzie, za pomocą niezbywalnego medium racji stanu, porozumienie okaże się w pehni możliwe. Przy czym - pamiętać trzeba - odpowiedzialność nie jest cnotą sensus stricto. Jest

\footnotetext{
${ }^{14}$ M. Weber, op. cit., s. 104.

${ }^{15}$ Ibidem, s. 102.

${ }^{16}$ Ibidem, s. 139.

${ }^{17}$ Ibidem, s. 75.
} 
ona czymś bardziej ogólnym - najogólniejszym rzec można. Jest sumą cnót kardynalnych. I w tym oto sensie „etyka przekonań i etyka odpowiedzialności nie są absolutnym przeciwieństwem, lecz się uzupełniaja, razem dopiero tworząc prawdziwego człowieka, który może mieć - i mieć będzie [przyp. - K. P.] - «powołanie do polityki»»"18.

${ }^{18}$ Ibidem, s. 110. 